\title{
Reviewing the Evaporites Interpretation using Well-Log Information in Santos Basin: Benefits and Applications
}

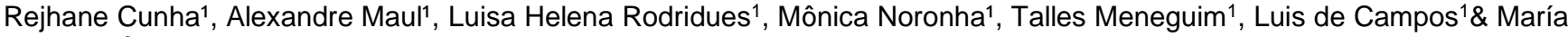

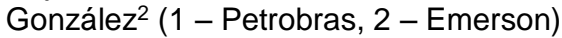

Copyright 2019, SBGf - Sociedade Brasileira de Geofísica

This paper was prepared for presentation during the $16^{\text {th }}$ International Congress of the Brazilian Geophysical Society held in Rio de Janeiro, Brazil, 19-22 August 2019

Contents of this paper were reviewed by the Technical Committee of the $16^{\text {th }}$ International Congress of the Brazilian Geophysical Society and do not necessarily represent any position of the SBGf, its officers or members. Electronic reproduction or storage of any part of this paper for commercial purposes without the written consent of the Brazilian Geophysical Society is prohibited.

\section{Abstract}

The last works developed by the Petrobras geological modeling group of seismic velocities of reservoir geophysics area shows the importance of incorporation of existing stratifications in the evaporitic section, Ariri Formation, is a key point in the improvement of Santos Basin Pre-Salt velocity models. The workflow proposed to generate a more realistic seismic velocity model has as key input data the 1D information of the wells, sonic velocity analysis with the aid of the lithologies interpreted along the entire stratigraphic column of the drilled wells. The generation of these lithology logs in the evaporitic and postevaporitic section is a careful work and may contain misunderstandings due to the absence of complete well log suites and, in the case of the evaporitic section, also due to the return only of the less soluble salts in the wellbore sample, basically halite and anhydrite. In order to create a more reliable common database, the lithologies of the evaporite and post evaporite sections of about 200 wells of the Santos Basin were reviewed. Besides drilling parameters, rock data, electrical profiles, field reports the seismic data were very important as guide for correlation among wells with a full suite of logs and wells not properlly logged. We present the impact on final reservoir geological and geophysical products such as: velocity model buiding, seismic reprocessing, seismic illumination studies, seismic depth uncertainty scenarios, generation of rock volume studies and geomechanical modeling.

\section{Introduction}

In the last few years, we have noticed the great evolution of seismic processing techniques, much because of increased computational capacity. This computational evolution has allowed the use of increasingly detailed velocity models. The detailing of velocity models therefore has been considered a key aspect to obtain the best seismic images. In particular, Jones and Davison (2014) mention difficulties in constructing seismic images in regions close to salt bodies as a function of velocity contrasts.
Since 2013, a Petrobras group dedicated to the geological modeling of seismic velocities in the area of reservoir geophysics has been working on the improvement of the models for the Pre-Salt fields of the Santos and Campos Basins. They were especially concerned with the incorporation of existing stratifications in the evaporitic section, the Retiro Formation in Campos Basin and the Ariri Formation in Santos Basin. This formation is an evaporite sequence deposited in a restricted marine transitional postrift environment of Cretaceous/Neapolitan age (Moreira et al., 2007), and can present variable thicknesses, reaching more than $3000 \mathrm{~m}$, as a function of the halokinese.

The recent results obtained are showing great value for the Santos Basin Pre-Salt projects (Maul et al., 2015, Jardim et al., 2015, Meneguim et al., 2015, Oliveira et al., 2015, González et al., 2016, Gobatto et al., 2016, Falcão, 2017, Fonseca et al., 2018). These studies cite the importance of an in-depth knowledge of the information obtained through well data, such as statistics of values obtained in well logs and lithological interpretation, as presented by Amaral et al., 2015 and Yamamoto et al., 2016). Cornelius and Castagna (2018) cite this same importance for projects in the Gulf of Mexico.

Figure 01 introduces the workflow for modeling stratified salt velocities, bringing the idea that all those steps permeated by the analysis of the seismic velocity logs, derived from the sonic logs, and its complements with the lithological descriptions.

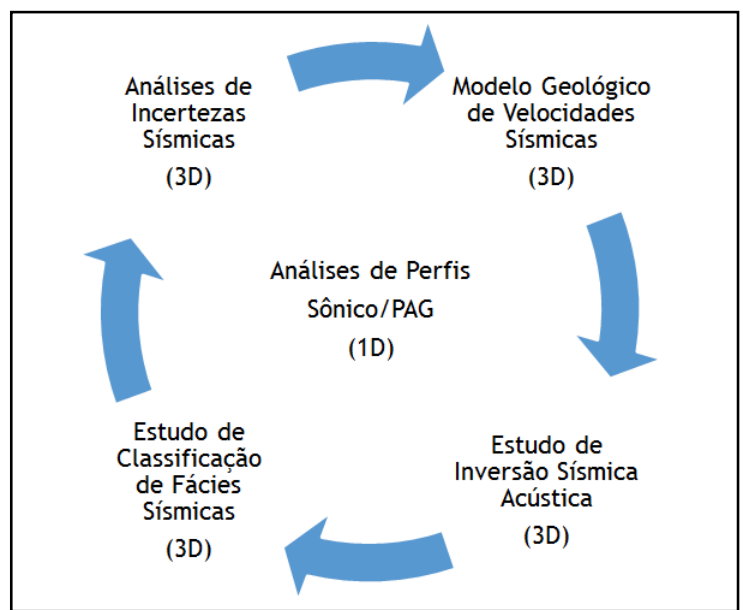

Figure 01: Proposed workflow to produce a more realistic velocity model, Maul et al. (2016). 
The possibility of produce and handle more detailed velocity models, including seismic inversion and facies modeling, reinforced the need to have a better lithological interpretation of the evaporite section, integrating data from rock samples, drilling parameters, geophysical logs and to correlations between seismic sections of the wells. However, as observed by Silva and Rodrigues (2016), the interpretation of the geological column during drilling of wells can generate different results, depending on the criteria used and the data acquired for this process. Despite needed, interpretation subjectivity in the composition of a geological column may generate errors of various sources.

At the beginning of 2016, Petrobras Pre-Salt reservoirs development department Santos Basin elected as one of the priority demands the revision of the lithological interpretations in the evaporite and post-evaporite section of all exploratory and development wells drilled. For a group of development wells, in the overburden section, only the well site geological logs were available, which is a draft lithological interpretation log performed onboard while or just after drilling, causing an absence of more detailed information.

This work aims to present the impact and results of these revised logs in several wells in the Santos Basin, assessing the benefits and identifying where these lithology logs are being used already, giving magnitude of integration work carried out by several company departments.

\section{Discussions}

Silva and Rodrigues (2016), present a technical discussion regarding criteria and data used to generate geological information of the evaporite section, in a more representative way, according to the reality, for the wells of the Pre-Salt of the Santos Basin. In their work, they demonstrated that the process of interpretation of the lithologies happens in a very dynamic and critical way, integrating data of different natures. This methodology generated new orientations for the composition of the interpreted geological column, with the aim of minimizing the frequent problems and mistakes in the interpretative process. For proper interpretation of well information several parameters should be considered, such as:

- Phase diameter: large annular diameters and / or whasouts will influence the responses obtained in the profiles (requiring at least a good control of the diameter of the well through the caliper logs);

- Drilling fluid: depending on the composition of the drilling fluid the well logs data may be compromised;

- Drilling parameters, such as: penetration rate, drill column weight and torque;

The penetration rate represents the natural resistance of rocks to drilling, and aids in lithological identification. The weight on column directly influences the penetration rate, i.e. it is important to observe both variables before inferring a certain type of lithology. A hard lithology should be hard to drill while a soft lithology should be easier, and weight on column should always be associated with the penetration rate and vice versa. The torque may be indicative of lithology change when variation of this parameter occurs only.

The association of the geophysical logs with the drilling parameters becomes essential for lithological identification, especially where there is no return of drill samples and / or also scarcity or lack of profiles. It is very common to drill the initial phases, not to return trough samples and run only the profiles of gamma rays and resistivity. This has been the path to be followed in order to obtain some information, called 1D, to aid in the 3D modeling of stratifications of the evaporite section. In this sense, the seismic sections between the wells also take on a great importance in this interpretation, see Figure 02.

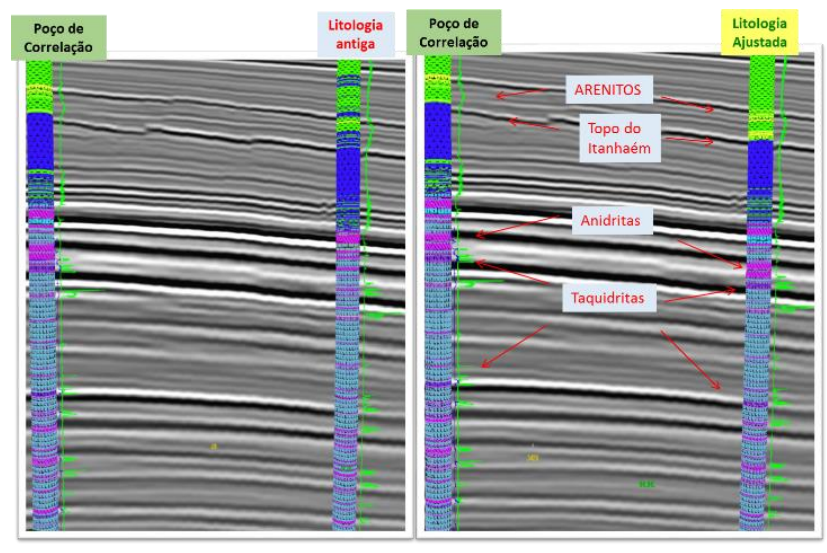

Figure 02: Well correlation and litology review based on seismic aided interpretation.

The result of the revision of the lithology log compared to the previously available log in the evaporitic section can be seen in Figure 03 for three Santos basin Pre-salt wells.

Currently, almost $100 \%$ of the wells drilled Santos Basin Pre-Salt play have already undergone this process of reviewing the lithology column in the evaporitic section. The newly drilled wells are being reviewed shortly after the completion of the drilling, in order to keep the lithology updated in the database.

The first product obtained directly from the generated lithology profiles is the proportion of the occurrence of the types of salts, now with $100 \%$ of its representability, per well, since the absence of profile records was complemented with the descriptions of the lithologies. Figure 04 shows the proportion of occurrence of salts, grouped according to their seismic velocities (low velocity salts, mainly represented by carnalites and tachyhydrites, "background" represented by halite, and salts of high velocities, represented by the anhydrite), in the wells studied. 


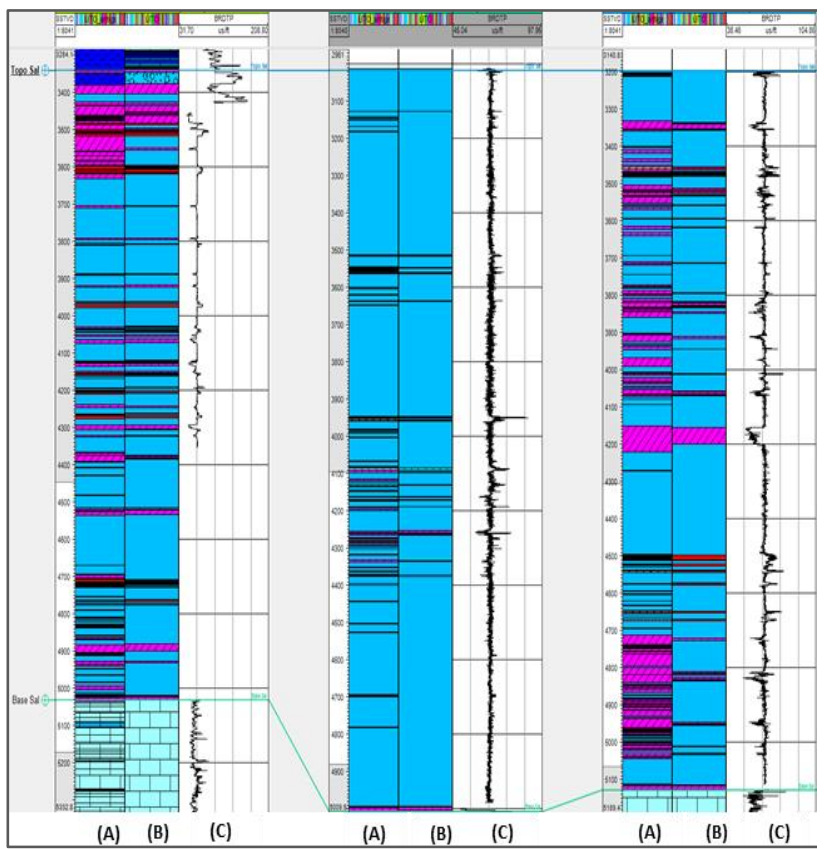

Figure 03: Comparison between two geological column interpretations. Old interpretations on the left $(A)$ of each track, and current interpretations center (B) and compressional sonic logs on the right $(C)$.

Amaral et al. (2015) and Yamamoto et al. (2016) indicate the predominance of halite therein, varying between 80 $90 \%$ and the remainder distributed between the "low salts" and "high salts". In terms of the occurrence of "types of salts", in their works, carried out in distinct areas, each with about 25 wells, these percentages are also observed in Gobatto et al. (2016), in this case considering about 150 wells, in the same basin, in different fields, and also in Jackson et al. (2015).

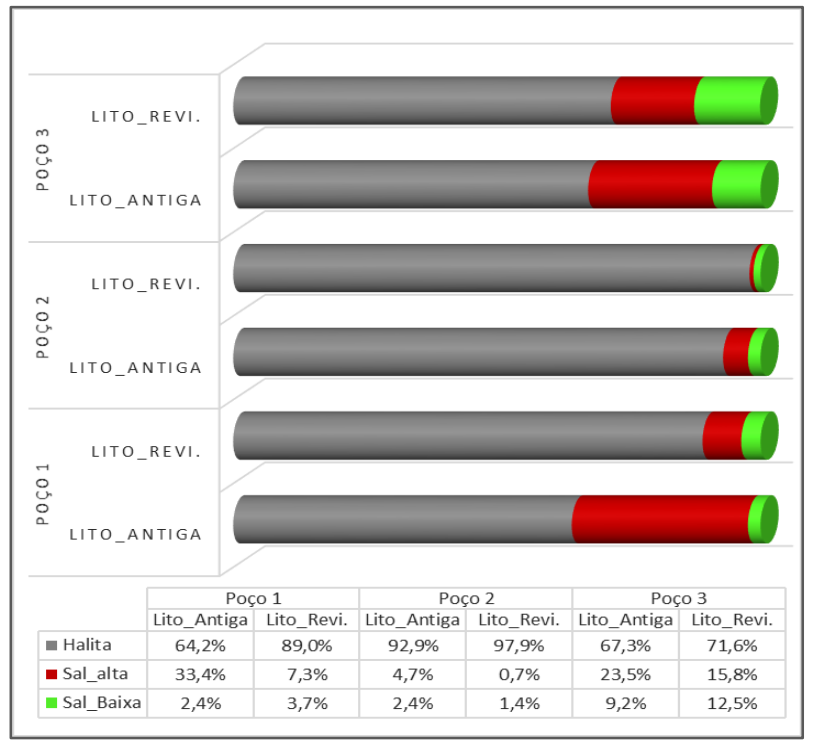

Figure 04: Proportion of the occurrence of salts in wells according to their seismic velocities: In gray halite (background), anhydrite red (high salt), and in green other salts (low salts)

Due to economic reasons, overburden lithologic column is not always logged for most of Santos Basin Pre-Salt development wells. Even in logged wells, we may not have the information across the drilling column due to technical problems, such as the phase transition region. The absence of this information compromises the realization of studies, which are now considered extremely important, in the process of modeling properties in the evaporite section, such as: velocity modeling, seismic-well tie, seismic inversion, facies and uncertainties.

With this new model of compressional velocities (vp), it is possible to infer, by correlations of well information, other properties (density, Young's Modulus, etc.) that can be used as inputs for other studies, such as: geomechanical simulation studies, framework of geological forecasts during the drilling of new wells, studies of seismic illumination for new acquisitions.

\section{Where to Apply the Methodoloty}

Illumination studies should always consider the geological nature in which the rays should be propagated to simulate a more realistic result. In this way, the insertion of the stratigraphy characterization to carry out these studies is mandatory .Figure 05 illustrates an example carried out in 2014 of refining geological modeling and velocities through well log reviewd. Note the smoothed result in $\mathrm{C}$ in comparision to $\mathrm{B}$.

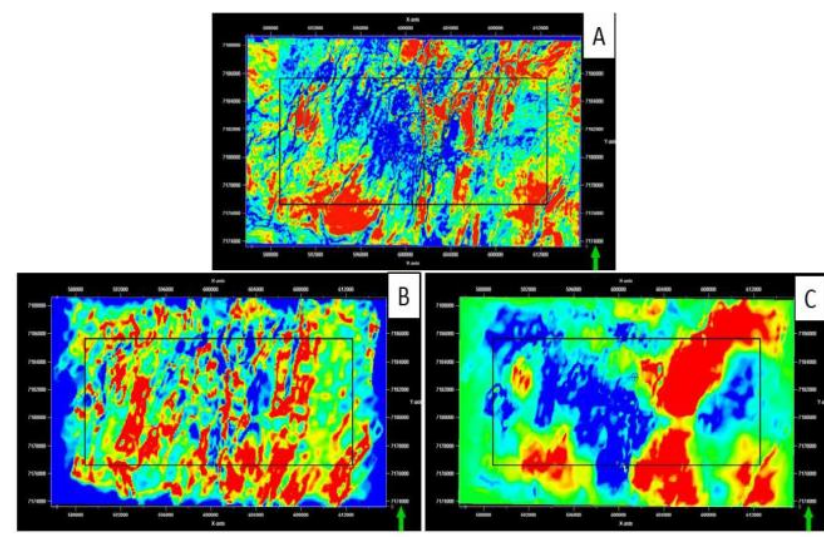

Figure 05: (A) Instantaneous amplitude at the top of the reservoir; (B) Simulated Amplitude at the top of the reservoir, from an illumination study regarding the original migration velocity; $(C)$ Simulated Amplitude at the top of the reservoir, from an illumination study regarding interval velocity with salt stratifications.

Seismic reprocessing, especially for those using more precise depth migration algorithms technique, such as the RTM (Reverse Time-Migration), requires models of velocities as close as possible to the existing geology. In this way, the insertion of the stratifications again becomes important. In even more advanced techniques, such as FWI (Full WaveForm Inversion), the initial model must always introduce the most accurate trend possible, in order to 
obtain a satisfactory final velocity model. The upgrades of the velocity models by tomographic inversions need to control how far they can operate (boundary conditions), that is referred to the stratifications.

Regarding operational safety during field development, especially in the drilling and well planning phases, the characterization of salt strata is an input of high geotechnical value. The generation of salts types and thickness depth scenarios to be drilled by the well path contributes to combat the occurrence of: drilling column imprisonment and dynamic drilling fluid loss from wells, often associated with soluble salts.

The estimation of the salt thickness that acts as a seal is also of great importance for the calculation of the maximum injection pressure of each well in the studies of geomechanical simulation of reservoirs, assuring the integrity of a sealing layer.

Figure 06 shows a session of the lithological model for the area of a pre-salt field of the Santos Basin obtained from seismic attributes and the lithologies reinterpreted in the wells. With special emphasis on the salt section: salt halite (in gray), salts of high impedance (purple) and salts of low impedance on (red).

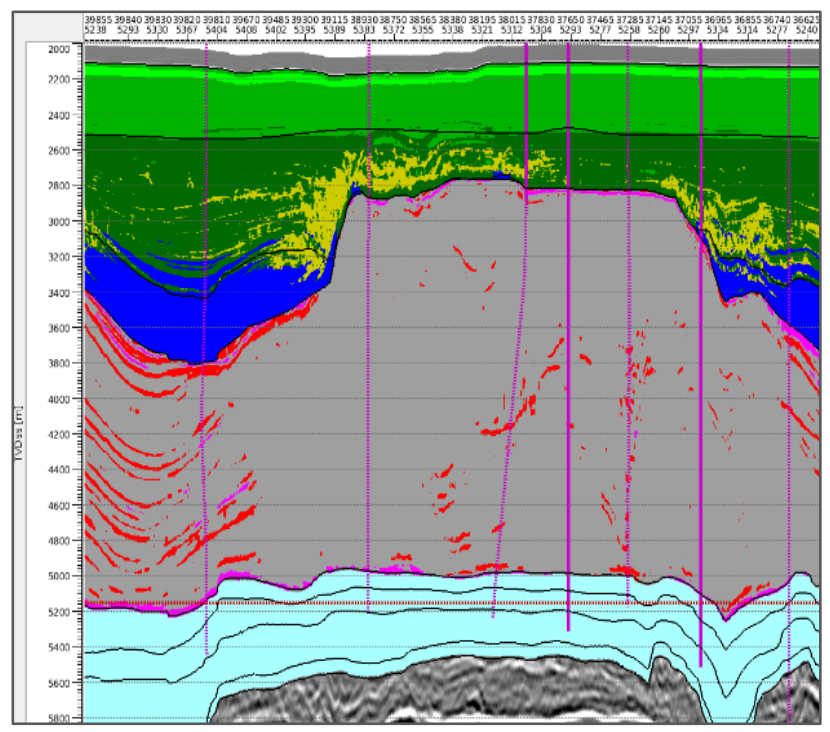

Figure 06: Lithological model in depth, obtained from reinterpreted wells lithologies and seismic attributes.

\section{Conclusions}

The ideal lithology interpretation should be performed using sonic and density logs, due to the nature of its investigation and easier identification of salt types. However, this is not a operational reality for the salt and post salt geological sections on Santos Basin Pre-Salt field development wells. In this work we argue that is possible to have a realistic interpretation of the evaporite section, from well data, seismic and rigorous technical foundations of well logs in the identification of salts and their mixtures. The vicious and misconceptions that resulted in a lower quality of interpretation occurrence is supposed to be due to the absence of acoustic profiles. In order to overcome the lack of sonic data we recommended that the lithological interpretation performed onboard also integrate different data sources such seismic data and well correlation to minimize errors and subjective interpretations.

The impact of the incorporation of the lithology profiles interpreted in the salt and post-salt sections of Santos Basin in the various types of geophysical studies is quite clear and promising.

\section{Acknowledgments}

The authors would like to thank Petrobras for providing the data and permission to publish this work, and Emerson E\&P Software for the support during this project.

\section{References}

Amaral, P.J., Maul, A., Falcão, L., González, M. \& González, G., 2015. Estudo Estatístico da Velocidade dos Sais na Camada Evaporítica na Bacia de Santos. 14th International Congress of the Brazilian Geophysical Society 2015 - Rio de Janeiro - RJ, Brazil.

Cornelius, S. \& Castagna, J. P. 2018. Variation in SaltBody Interval Velocities in the Deepwater Gulf of Mexico: Keathley Canyon and Walker Ridge Areas. Interpretation, Vol. 6, No. 1 (February 2018); p. T15-T27.

Falcão L. 2017. O Sal Estratificado e sua Importância na Modelagem de Velocidades para Fins de Migração Sísmica. Dissertação de Mestrado, UFF, Dinâmica Oceânica e Costeira - DOT, 91 f. il. (color.), Niterói, RJ, Brazil.

Fonseca, J., Teixeira, L., Maul, A., Barros, P., Boechat, J. \& González, M., 2018. Modelling Geological Layers into new Velocity Models for Seismic Migration Process: A Brazilian pre-Salt Case. (First EAGE/PESGB Workshop on Velocities). London, United Kingdom.

Gobatto, F., Maul, A., Falcão, L., Teixeira, L., Boechat, J.B., González, M. \& González, G., 2016. Refining Velocity Model within the Salt Section in Santos Basin: an Innovative Workflow to include the Existing Stratification and its Considerations. (SEG - Society of Exploration Geophysicist - 2016) - Dallas - TX, USA.

González, M., Gobatto, F., Maul, A., Falcão, L., González, G., Oliveira, L., Meneguim, T. \& Amaral, P.J., 2016. Proposed Workflow to Incorporate Stratification within Salt Section using Velocity and Seismic Attributes. Third EAGE/SBGf Workshop - Rio de Janeiro - RJ, Brazil.

Jackson, C.A.-L., Jackson, M.P.A., Hudec, M.R. \& Rodriguez, C.R., 2015. Enigmatic Structures within Salt Walls of Santos Basin - Part 1: Geometry and Kinematics from 3D Seismic Reflection and Well Data. (Journal of Structural Geology, 75, 135-162. 
Jardim, F., Maul, A., Falcão, L., \& González, G., 2015. Estimating Amplitude Uncertainties through Illumination Studies for a Pre-Salt Reservoir. 14th International Congress of the Brazilian Geophysical Society 2015 - Rio de Janeiro - RJ, Brazil.

Jones, I. F. \& Davison I., 2014. Seismic Imaging in and around Salt Bodies. Interpretation, Vol. 2, No.4, SL1-SL20.

Maul A, Falcão L, Gobatto F, Novellino V, Jardim F, Oliveira L, Meneguim T, Amaral PJ, Borges F, Teixeira L, Monteiro RC, González G \& González M. 2016. Incorporação de Estratificações dentro da Seção Evaporítica Utilizando Velocidades e Atributos Sísmicos (Informe Geofísico da Petrobras - IGP-152 - Petrobras Internal Publication).

Maul, A., Jardim, F., Falcão, L., \& González, G., 2015. Observing Amplitude Uncertainties for a Pre-salt Reservoir Using Illumination Study (Hit-Maps). 77th EAGE Conference \& Exhibition 2015 - Madrid, Spain.

Moreira, J.L.P., Madeira, C.V., Gil, J.A. \& Machado, M.A.P., 2007. Boletim de Geociências da Petrobras. Rio de Janeiro, v. 15, n. 2, 572 p.p.531-549.

Meneguim, T., Mendes, S., Maul, A., Falcão, L., González, M. \& González, G., 2015. Combining Seismic Facies Analysis and Well Information to Guide New Interval Velocity Models for a Pre-Salt Study, Santos Basin, Brazil. 14th International Congress of the Brazilian Geophysical Society 2015 - Rio de Janeiro - RJ, Brazil.

Oliveira, L., Falcão, L., Maul, A., Rosseto, J., González, M. \& González, G., 2015. Geological Velocity Approach in Order to Obtain a Detailed Velocity Model for the Evaporitic Section, Santos Basin. 14th International Congress of the Brazilian Geophysical Society 2015 - Rio de Janeiro - RJ, Brazil.

Silva, D.B. \& Rodrigues, L.H.O., 2016. Critérios para Interpretação da Coluna Geológica da Fm. Ariri Sequência Evaporítica da Bacia de Santos. (STOG Seminário Técnico de Operações Geológicas da Petrobras - Petrobras Internal Publication). Rio de Janeiro - RJ.

Yamamoto, T., Maul, A., Born, E., Gobatto, F., Campos, M.T. \& González, M., 2016. Incorporação de Estratificações Salíferas Através do Modelo de Velocidade em um Projeto da Bacia de Santos (VII Simpósio Brasileiro de Geofísica - 2016). Ouro Preto - MG, Brazil. 